\title{
Description of Sphingobium fuliginis sp. nov., a phenanthrene-degrading bacterium from a fly ash dumping site, and reclassification of Sphingomonas cloacae as Sphingobium cloacae comb. nov.
}

Correspondence

Rup Lal

duzdel@vsnl.com

\author{
Om Prakash and Rup Lal \\ Molecular Biology Laboratory, Department of Zoology, University of Delhi, Delhi - 110 007, \\ India
}

\begin{abstract}
A phenanthrene-degrading bacterium, strain $\mathrm{TKP}^{\top}$, was isolated from a fly ash dumping site of the thermal power plant in Panki, Kanpur, India, by an enrichment culture method using phenanthrene as the sole source of carbon and energy. Phylogenetic analysis based on 16S rRNA gene sequences indicated that the strain belonged to the genus Sphingobium, as it showed highest sequence similarity to Sphingobium herbicidovorans DSM $11019^{\top}(97 \cdot 3 \%)$ and Sphingomonas cloacae JCM $10874^{\top}(96 \cdot 5 \%)$, compared with only $91-93 \%$ similarity to members of other genera such as Sphingomonas sensu stricto, Novosphingobium, Sphingopyxis and Sphingosinicella. In DNADNA hybridization experiments with strains that were closely related phylogenetically and in terms of 16S rRNA gene sequences, i.e. Sphingobium herbicidovorans DSM $11019^{\top}$ and Sphingomonas cloacae JCM $10874^{\top}$, strain $\mathrm{TKP}^{\top}$ showed less than $70 \%$ relatedness. Strain $\mathrm{TKP}^{\top}$ contained sphingoglycolipids SGL-1 and SGL-2 and $18: 1 \omega 7 c$ as the predominant fatty acid, with $16: 0$ as a minor component and 14:0 2-OH as the major 2-hydroxy fatty acid. Thus, phylogenetic analysis, DNA-DNA hybridization, fatty acid and polar lipid profiles and differences in physiological and morphological features from the most closely related members of the Sphingobium group showed that strain TKP ${ }^{\top}$ represents a distinct species of Sphingobium. The name Sphingobium fuliginis sp. nov. is proposed, with the type strain $\operatorname{TKP}^{\top}\left(=\right.$ MTCC $7295^{\top}=$ CCM $\left.7327^{\top}\right)$. Sphingomonas cloacae JCM $10874^{\top}$ formed a coherent cluster with members of Sphingobium, did not reduce nitrate to nitrite and had a fatty acid profile similar to those of Sphingobium species; hence Sphingomonas cloacae should be transferred to the genus Sphingobium as Sphingobium cloacae comb. nov., with the type strain JCM $10874^{\top}$ (=DSM $14926^{\top}$ ).
\end{abstract}

Phenanthrene is a member of the polycyclic aromatic hydrocarbon $(\mathrm{PAH})$ group, a class of hydrophobic organic compounds. It is a constituent of petroleum hydrocarbons and coal, originating from incomplete combustion of organic materials such as coal and oil, and of tobacco smoke. Phenanthrene is distributed abundantly in higher concentrations around coal gasification sites, fly ash dumping sites of coal-fired thermal power plants and petroleum-contaminated sites of oil refineries. It is persistent in nature, it is a human skin photosensitizer and a mild allergen and is toxic to aquatic organisms (Pipe \& Moore, 1986). Contamination of

The GenBank/EMBL/DDBJ accession number for the 16S rRNA gene sequence of strain $\mathrm{TKP}^{\top}$ is DQ092757.

Details of the polar lipid and fatty acid profiles of strain $\mathrm{TKP}^{\top}$ and related strains and a two-dimensional TLC of polar lipids of strain TKP are available as supplementary material in IJSEM Online. the environment by phenanthrene has created several environmental problems.

In the present study, a phenanthrene-degrading, yellowpigmented bacterium, strain $\mathrm{TKP}^{\mathrm{T}}$, was isolated from a fly ash dumping site of the thermal power plant in Panki, Kanpur, India, by an enrichment culture approach using phenanthrene as the sole source of carbon and energy. Phylogenetic and taxonomic characterization of the strain using a polyphasic approach revealed that the strain represents a novel species of Sphingobium. We also reclassify Sphingomonas cloacae as Sphingobium cloacae comb. nov. based on its greater similarity to members of Sphingobium than to members of other related genera.

Strain $\mathrm{TKP}^{\mathrm{T}}$ was screened for phenanthrene degradation as described by Kiyohara et al. (1982). Colonies producing a clear zone by degradation of phenanthrene were picked and 
purified by restreaking several times on nutrient agar (NA) plates. Strain $\mathrm{TKP}^{\mathrm{T}}$ produced a clear zone of phenanthrene degradation after $48 \mathrm{~h}$ of incubation and utilized more than $200 \mathrm{mg}$ phenanthrene $\mathrm{l}^{-1}$ within $24 \mathrm{~h}$ in liquid culture (data not shown).

\section{5 rRNA gene sequencing and analysis}

Genomic DNA from strain $\mathrm{TKP}^{\mathrm{T}}$ was extracted using the method of Kaur et al. (2001). The 16S rRNA gene sequence of strain $\mathrm{TKP}^{\mathrm{T}}$ was obtained from the Sherlock Microbial Identification System (Microbial ID Inc.). Similarity searches were done using the sequence match program of the Ribosomal Database Project (http://rdp.cme.msu.edu/ $\mathrm{html} /$ ) and the BLAST program of the National Center for Biotechnological Information (http://www.ncbi.nlm.nih. gov).

$16 \mathrm{~S}$ rRNA gene sequences ( $>1200 \mathrm{bp}$ ) of 38 established species of the genera Sphingomonas sensu stricto, Sphingobium, Novosphingobium, Sphingopyxis and Sphingosinicella were retrieved and their similarity to the $16 \mathrm{~S}$ rRNA gene sequence of strain $\mathrm{TKP}^{\mathrm{T}}$ was analysed. For construction of the tree, 16S rRNA gene sequences of strain $\mathrm{TKP}^{\mathrm{T}}$, Blastomonas ursincola DSM $9006^{\mathrm{T}}$, Blastomonas natatoria DSM $3183^{\mathrm{T}}$ and all members of Sphingobium with validly published names along with type strains of the genera Sphingomonas sensu stricto, Novosphingobium, Sphingopyxis and Sphingosinicella (Maruyama et al., 2006) were selected. The 16S rRNA gene sequence of Zymomonas mobilis ATCC $10988^{\mathrm{T}}$ was used as an outgroup. Selected sequences were aligned using the CLUSTAL X program (Thompson et al., 1997), gaps common to all the selected sequences were removed and the alignment was checked manually for quality. Terminal nucleotides not common to all the sequences were removed. Phylogenetic analysis was carried out using the PHYLIP package version 3.5c (Felsenstein, 1993). An evolutionary distance matrix was calculated using the distance model of Jukes \& Cantor (1969). The evolutionary tree (Fig. 1) was constructed using the neighbour-joining method (Saitou \& Nei, 1987) and the resultant tree topology was evaluated by bootstrap analysis based on 100 resamplings, using the SEQBOOT and CONSENSE programs in the PHYLIP package. Parsimony analysis was also performed for the aligned sequence data using DNAPARS including bootstrap analysis with 100 resamplings.

Evaluation of the tree topology (Fig. 1) revealed that strain $\mathrm{TKP}^{\mathrm{T}}$ clustered with species represented by the genus Sphingobium and formed a monophyletic clade with Sphingobium herbicidovorans DSM $11019^{\mathrm{T}}$. Similar tree topology and clustering were also obtained by the maximum-parsimony method of the PHYLIP package (data not shown). Strain $\mathrm{TKP}^{\mathrm{T}}$ showed $95 \cdot 9-97 \cdot 3 \% 16 \mathrm{~S}$ rRNA gene sequence similarity to members of Sphingobium, in contrast with only 91-93\% sequence similarity to members of Sphingomonas sensu stricto, Novosphingobium, Sphingopyxis and Sphingosinicella. This indicated that strain $\mathrm{TKP}^{\mathrm{T}}$ is a member of Sphingobium. The highest $16 \mathrm{~S}$

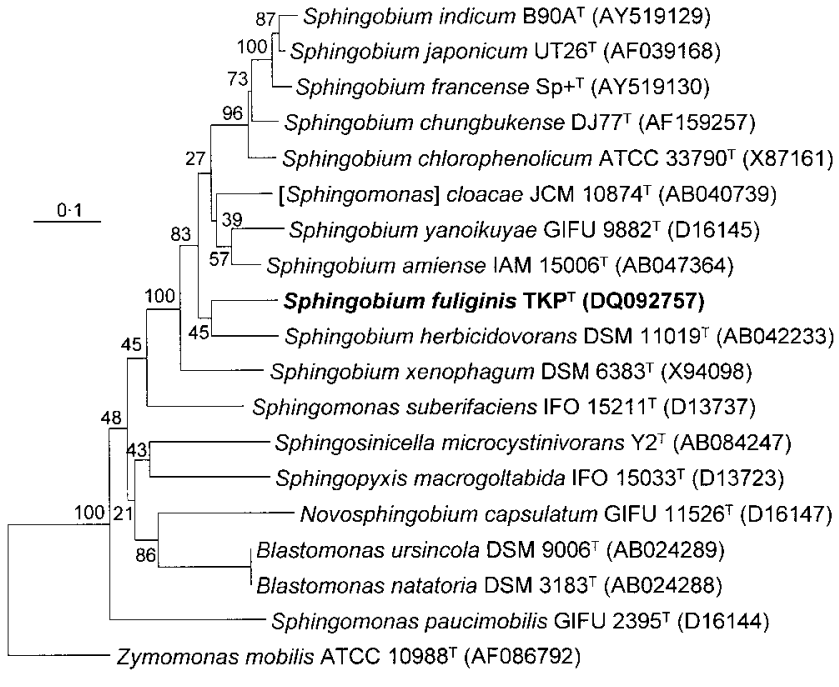

Fig. 1. Phylogenetic tree based on nearly complete 16S rRNA gene sequences showing the relationship of strain $\operatorname{TKP}^{\top}$ to Sphingobium herbicidovorans DSM $11019^{\top}$ and Sphingomonas cloacae JCM $10874^{\top}$ and related species. The tree was constructed by the neighbour-joining method and was rooted by using Zymomonas mobilis ATCC $10988^{\top}$ as the outgroup. Numbers at nodes represent bootstrap values (based on 100 resamplings). Bar, $0 \cdot 1$ nucleotide substitution per nucleotide position.

rRNA gene sequence similarity of strain $\mathrm{TKP}^{\mathrm{T}}$ was found to the sequences of Sphingobium herbicidovorans DSM $11019^{\mathrm{T}}$ $(97 \cdot 3 \%)$, the nearest relative of strain $\mathrm{TKP}^{\mathrm{T}}$ in the phylogenetic tree, followed by Sphingomonas cloacae JCM $10874^{\mathrm{T}}(96 \cdot 5 \%)$ (Fig. 1).

\section{DNA-DNA hybridization}

DNA-DNA hybridization was carried out in order to check the delineation of strain $\mathrm{TKP}^{\mathrm{T}}$ from its closest phylogenetic relative, Sphingobium herbicidovorans DSM $11019^{\mathrm{T}}$, as well as Sphingomonas cloacae JCM $10874^{\mathrm{T}}$, which is closely related phylogenetically and in terms of $16 \mathrm{~S}$ rRNA gene sequence similarity. DNA extraction, purification and hybridization were done as described by Pal et al. (2005). The amount of bound probe DNA was estimated by using a scintillation counter (Beckman Instruments) and levels of hybridization were expressed as the percentage of probe bound relative to the homologous reaction.

In DNA-DNA hybridization experiments, strain $\mathrm{TKP}^{\mathrm{T}}$ showed only $11 \%$ relatedness with Sphingobium herbicidovorans DSM $11019^{\mathrm{T}}$ and $14 \%$ relatedness with Sphingomonas cloacae JCM $10874^{\mathrm{T}}$. Similar results were obtained when labelled DNA of Sphingobium herbicidovorans DSM $11019^{\mathrm{T}}$ or Sphingomonas cloacae JCM $10874^{\mathrm{T}}$ was used as the probe. These levels of DNA-DNA hybridization are much less than the threshold value $(70 \%)$ suggested for bacterial species delineation by Wayne et al. (1987). Thus, DNA-DNA hybridization clearly delineated strain $\mathrm{TKP}^{\mathrm{T}}$ from the most 
closely related strains, Sphingobium herbicidovorans DSM $11019^{\mathrm{T}}$ and Sphingomonas cloacae JCM $10874^{\mathrm{T}}$.

\section{Polar lipid and fatty acid methyl ester analysis}

Fatty acid profiles of strain $\mathrm{TKP}^{\mathrm{T}}$ and Sphingomonas cloacae JCM $10874^{\mathrm{T}}$ were obtained from the Sherlock Microbial Identification System (Microbial ID Inc.). For this purpose, the bacterium was grown on trypticase soya broth agar (TSBA) at $28^{\circ} \mathrm{C}$ and fatty acids were saponified, methylated and extracted as described by Miller (1982) and Kuykendall et al. (1988). Polar lipid analysis was carried out by the identification service of the DSMZ (Braunschweig, Germany) as described by Tindall (1990a, b).

Fatty acids of strain $\mathrm{TKP}^{\mathrm{T}}$ along with phylogenetically close members of Sphingobium are detailed in Supplementary Table S1 (available in IJSEM Online). The predominance of $18: 1 \omega 7 c$ and high levels of $16: 0$ in strain $\mathrm{TKP}^{\mathrm{T}}$ indicated that the strain is a member of the Alphaproteobacteria. The presence of 2-hydroxy fatty acids and the absence of 3hydroxy fatty acids (features common to sphingomonads) further indicated that strain $\mathrm{TKP}^{\mathrm{T}}$ is a member of the family Sphingomonadaceae (Busse et al., 1999). Like other members of Sphingobium, Novosphingobium, Sphingopyxis and Sphingosinicella, it also contains 14:02-OH as the major 2-hydroxy fatty acid. However, the presence of 16:0 2-OH differentiated strain $\mathrm{TKP}^{\mathrm{T}}$ from members of the genera Sphingomonas and Novosphingobium, since 16:0 2-OH is not found in members of these genera (Takeuchi et al., 2001), and indicated that the strain could be a member of Sphingobium or Sphingopyxis. Further, the presence of only a minor amount of 16:0 2-OH (a major component in Sphingopyxis) and the lower level of 16S rRNA gene sequence similarity of strain $\mathrm{TKP}^{\mathrm{T}}$ with members of Sphingopyxis (91-93\%) compared with Sphingobium (95-97\%) justified the clustering of strain $\mathrm{TKP}^{\mathrm{T}}$ in a clade represented by the genus Sphingobium.

The polar lipids phosphatidylethanolamine, phosphatidylglycerol, diphosphatidylglycerol, phosphatidylcholine and sphingoglycolipids, commonly found in other sphingomonads, were also detected in strain $\mathrm{TKP}^{\mathrm{T}}$ (see Supplementary Fig. S1 and Supplementary Table S2 available in IJSEM Online). From comparison of lipid profiles, it appears that SGL-1 of strain $\mathrm{TKP}^{\mathrm{T}}$ probably corresponds to SGL of Sphingobium yanoikuyae IFO $15102^{\mathrm{T}}$ and either GL-4 or SGL of Sphingomonas macrogoltabidus IFO $15033^{\mathrm{T}}$, while SGL-2 represents GL-1 of Sphingobium yanoikuyae IFO $15102^{\mathrm{T}}$ and SGL or GL-1 of Sphingomonas macrogoltabidus IFO $15033^{\mathrm{T}}$ (Busse et al., 1999). It was also noted that the aminophospholipid (PN) of strain $\mathrm{TKP}^{\mathrm{T}}$ probably corresponds to phosphatidylmonomethylethanolamine (PME) and the unidentified phospholipid (PL) to phosphatidyldimethylethanolamine (PDE) of Busse et al. (1999).

The presence of sphingoglycolipids confirms only that strain $\mathrm{TKP}^{\mathrm{T}}$ is a member of the family Sphingomonadaceae
(Yabuuchi et al., 1990; Busse et al., 1999; Takeuchi et al., 2001), but comparison of the polar lipids and fatty acids of strain $\mathrm{TKP}^{\mathrm{T}}$ with phylogenetically close members of Sphingobium showed the presence of similar profiles and confirmed that strain $\mathrm{TKP}^{\mathrm{T}}$ is a member of genus Sphingobium.

\section{Phenotypic characterization}

Morphological features of the colonies (shape, size, colour, contour and pigment production) were studied on NA and Luria-Bertani (LB) agar plates after $72 \mathrm{~h}$ of incubation at $30{ }^{\circ} \mathrm{C}$. Strain $\mathrm{TKP}^{\mathrm{T}}$ formed yellow-coloured, circular, smooth colonies, 1.5 and $2.0 \mathrm{~mm}$ in diameter, respectively, on NA and LB agar plates. Gram staining and spore staining were done using a Himedia kit. The cell size was measured by micrometry. Motility of the organism was studied by the hanging drop method as well as on motility agar (Table 1). Antibiotic sensitivity tests were performed on MuellerHinton II medium using Readymade Sensi-Discs (Himedia). Growth at different temperatures was examined and the catalase test was carried out as described by McCarthy \& Cross (1984). Biochemical tests were performed as described by Pal et al. (2005). Hydrolysis of Tween 20 and 80 and the ability of the strain to grow in the presence of $\mathrm{NaCl}$ were tested as described by Arden-Jones et al. (1979). Urease activity was detected as described by Christensen (1946). Acid production from carbohydrates and degradation of xanthine and hypoxanthine were tested as described by Gordon et al. (1974). The other physiological tests and methods were described by Collins et al. (1989). Phenanthrene-degrading activity of the strain was tested by gas chromatography (Samanta et al., 1999).

Pigments were extracted in chloroform/methanol $(2: 1)$ (Goel et al., 2001) and in acetone (Jenkins et al., 1979). Absorption maxima $\left(\lambda_{\max }\right)$ of the pigment in chloroform/ methanol and in acetone extracts were 254 and $211 \mathrm{~nm}$, respectively. Strain $\mathrm{TKP}^{\mathrm{T}}$ also produced a water-soluble yellow pigment $\left(\lambda_{\max } 230 \mathrm{~nm}\right)$ distinct from the watersoluble brown pigment of Sphingobium herbicidovorans DSM $11019^{\mathrm{T}}$. Nitrate reduction is common to species of Sphingomonas and Novosphingobium but has not been reported so far for Sphingobium. However, unlike other members of Sphingobium, strain $\mathrm{TKP}^{\mathrm{T}}$ showed a weakly positive test for nitrate reduction. In conclusion, 16S rRNA gene sequence analysis, comparative study of fatty acid and lipid profiles, pigment analysis, morphological features, biochemical tests (Table 1) and DNA-DNA hybridization with the most closely related members of Sphingobium differentiated strain $\mathrm{TKP}^{\mathrm{T}}$ from these species and indicated that strain $\mathrm{TKP}^{\mathrm{T}}$ represents a novel species of Sphingobium, for which the name Sphingobium fuliginis sp. nov. is proposed.

During the classification of strain $\mathrm{TKP}^{\mathrm{T}}$, it was found that Sphingomonas cloacae JCM $10874^{\mathrm{T}}$ clustered with members of Sphingobium and not with Sphingomonas. It also showed the highest 16S rRNA gene sequence similarity $(95-97 \%)$ to 
Table 1. Differential phenotypic characteristics of strain $\mathrm{TKP}^{\top}$ and phylogenetically close members of the genus Sphingobium

Strains: 1, strain $\mathrm{TKP}^{\mathrm{T}}$ (data from this study); 2, Sphingomonas cloacae JCM 10817 ${ }^{\mathrm{T}}$; 3, Sphingobium herbicidovorans DSM $11019^{\mathrm{T}}$; 4, Sphingobium yanoikuyae IFO $15102^{\mathrm{T}}$ (unless indicated otherwise, data in columns 2-4 were taken from Yabuuchi et al., 2002); 5, Sphingobium amiense IAM $15006^{\mathrm{T}}$ (data from Ushiba et al., 2003). All strains showed positive results for oxidase, catalase and assimilation of maltose and negative results for urease and assimilation of lactose, inositol and sorbitol. +, Positive; - , negative; w, weakly positive; ND, no data available.

\begin{tabular}{|c|c|c|c|c|c|}
\hline Character & 1 & 2 & 3 & 4 & 5 \\
\hline Colour & Yellow & Creamy white & Yellow & Light yellow & Creamy yellow \\
\hline Motility & - & - & + & + & + \\
\hline Cell size $(\mu \mathrm{m})$ & $0.5 \times 1.5$ & $1 \cdot 1 \times 3 \cdot 1$ & $0 \cdot 4 \times 2 \cdot 1$ & $0 \cdot 7 \times 3 \cdot 5$ & $1 \cdot 1 \times 1 \cdot 7$ \\
\hline Water-soluble pigment & Yellow & ND & Brown & ND & ND \\
\hline Optimum growth temperature $\left({ }^{\circ} \mathrm{C}\right)$ & 37 & 25 & 28 & 28 & 27 \\
\hline Degradation of nonylphenol & ND & + & ND & ND & + \\
\hline \multicolumn{6}{|l|}{ Hydrolysis of: } \\
\hline Gelatin & - & - & + & - & - \\
\hline Aesculin & - & + & + & + & - \\
\hline Nitrate reductase & $\mathrm{w}$ & $-{ }^{\star}$ & $-{ }^{\star}$ & - & - \\
\hline \multicolumn{6}{|l|}{ Acid production from: } \\
\hline Adonitol & $\mathrm{W}$ & - & + & - & ND \\
\hline Dulcitol & - & - & + & - & ND \\
\hline Glucose & + & - & + & + & - \\
\hline Mannitol & - & - & + & - & $\mathrm{ND}$ \\
\hline Ribose & $\mathrm{W}$ & - & - & + & $\mathrm{ND}$ \\
\hline Xylose & + & - & + & + & $\mathrm{ND}$ \\
\hline Arabinose & + & - & - & - & - \\
\hline
\end{tabular}

${ }^{\star}$ Data from this study.

members of Sphingobium, in contrast to only 91-94\% similarity to members of other genera such as Sphingomonas sensu stricto, Novosphingobium, Sphingopyxis, Sphingosinicella and Blastomonas. Phylogenetic trees published previously (Fujii et al., 2001; Yabuuchi et al., 2002; Pal et al., 2005) revealed a similar position for Sphingomonas cloacae JCM $10874^{\mathrm{T}}$. In addition, examination of the fatty acid profile of Sphingomonas cloacae JCM $10874^{\mathrm{T}}$ (from this study) showed that, in common with most members of Sphingobium, it also contains $18: 1 \omega 7 c$ as the dominant fatty acid with $16: 0$ as a minor component and 14:0 2-OH as the major 2-hydroxy fatty acid (Supplementary Table S1). It did not reduce nitrate to nitrite, a characteristic feature of all members of Sphingobium (Takeuchi et al., 2001), supporting its position with members of Sphingobium. The paper by Takeuchi et al. (2001) on the division of Sphingomonas into Sphingomonas sensu stricto and three new genera, Sphingobium, Novosphingobium and Sphingopyxis, and the description of Sphingomonas cloacae by Fujii et al. (2001) were published in the same volume of the International Journal of Systematic and Evolutionary Microbiology. Thus, data for Sphingomonas cloacae JCM $10874^{\mathrm{T}}$ were not available to Takeuchi et al. (2001) for analysis and reclassification. Therefore, we also propose the transfer of Sphingomonas cloacae to the genus Sphingobium as Sphingobium cloacae comb. nov.

\section{Description of Sphingobium fuliginis sp. nov.}

Sphingobium fuliginis (fu.li'gi.nis. L. gen. n. fuliginis of soot, referring to the coal fly ash from which the type strain was isolated).

Gram-negative, strictly aerobic, non-spore-forming, nonmotile, small rod $(0 \cdot 7-1 \cdot 0 \mu \mathrm{m})$. Colonies are yellowpigmented, small (diameter $1.5 \mathrm{~mm}$ on NA and $2.0 \mathrm{~mm}$ on LB agar after $72 \mathrm{~h}$ of incubation at $30^{\circ} \mathrm{C}$ ), entire, smooth and circular. Positive in tests for oxidase, catalase and nitrate reductase but gives negative results in tests for gelatinase, urease and amylase. Acids are produced from glucose, maltose, D-ribose, xylose and adonitol (after a long incubation) but not from inositol, sucrose, dulcitol, mannitol or sorbitol. Grows at $20-37^{\circ} \mathrm{C}$ but not at 10 or $40{ }^{\circ} \mathrm{C}$. The optimum temperature for growth is $37^{\circ} \mathrm{C}$. Sensitive to $5 \% \mathrm{NaCl}$ and does not grow at $\mathrm{pH} 10$. Sensitive to discs containing nalidixic acid $(30 \mu \mathrm{g})$, tetracycline $(30 \mu \mathrm{g})$, gentamicin $(10 \mu \mathrm{g})$, chlortetracycline $(30 \mu \mathrm{g})$, rifamycin $(5 \mu \mathrm{g})$, oxytetracycline $(30 \mu \mathrm{g})$, neomycin $(30 \mu \mathrm{g})$, kanamycin $(30 \mu \mathrm{g})$ and novobiocin $(30 \mu \mathrm{g})$ and resistant to vancomycin $(30 \mu \mathrm{g})$, penicillin $\mathrm{G}(10 \mu \mathrm{g})$, ampicillin $(10 \mu \mathrm{g})$, streptomycin $(10 \mu \mathrm{g})$, amoxicillin $(10 \mu \mathrm{g})$ and erythromycin $(15 \mu \mathrm{g})$. Together with glycosphingolipids (SGL-1 and SGL-2), the polar lipid profile also 
contains phosphatidylethanolamine, phosphatidylglycerol, diphosphatidylglycerol, phosphatidylcholine, an unidentified glycolipid, unidentified phospholipids and an aminophospholipid. The fatty acid profile of the type strain contains $14: 0(0 \cdot 45 \%), 15: 0(0 \cdot 24 \%), 16: 0(8 \cdot 33 \%)$, $18: 0(0 \cdot 30 \%), 20: 0(0 \cdot 24 \%), 14: 02-\mathrm{OH}(10 \cdot 51 \%), 16: 0$ $2-\mathrm{OH}(0 \cdot 52 \%), 16: 1 \omega 5 c(1 \cdot 29 \%), 15: 02-\mathrm{OH}(0 \cdot 44 \%)$, $17: 1 \omega 8 c(0 \cdot 28 \%), 17: 1 \omega 6 c(1 \cdot 70 \%), 18: 1 \omega 7 c(65 \cdot 80 \%)$, $18: 1 \omega 5 c(0 \cdot 97 \%)$ and 11 -methyl $18: 1 \omega 7 c(1 \cdot 16 \%)$.

The type strain, strain $\mathrm{TKP}^{\mathrm{T}}\left(=\mathrm{MTCC} 7295^{\mathrm{T}}=\mathrm{CCM}\right.$ $7327^{\mathrm{T}}$ ), was isolated from a fly ash dumping site of the thermal power plant at Panki, Kanpur, India, and degrades phenanthrene efficiently on solid medium (plates sprayed with phenanthrene) as well as in liquid culture.

\section{Description of Sphingobium cloacae (Fujii et al. 2001) comb. nov.}

Sphingobium cloacae (clo.a'cae. L. gen. n. cloacae of a sewer, the source of the type strain).

Basonym: Sphingomonas cloacae Fujii et al. 2001.

The description is identical to that of Sphingomonas cloacae as given by Fujii et al. (2001). The type strain is JCM $10874^{\mathrm{T}}$ $\left(=\right.$ DSM $14926^{\mathrm{T}}=$ CIP $107076^{\mathrm{T}}=$ IAM $\left.14885^{\mathrm{T}}\right)$.

\section{Acknowledgements}

Part of this work was supported by grants from the Department of Biotechnology (DBT), Government of India. O. P. gratefully acknowledges CSIR-UGC, Government of India, for providing research fellowships. We would like to thank J. P. Euzéby for etymological advice.

\section{References}

Arden-Jones, M. P., McCarthy, A. J. \& Cross, T. (1979). Taxonomic and serological studies on Micropolyspora faeni and Micropolyspora strains from soil bearing the specific epithet rectivirgula. $J$ Gen Microbiol 115, 343-354.

Busse, H. J., Kämpfer, P. \& Denner, E. B. M. (1999). Chemotaxonomic characterization of Sphingomonas. J Ind Microbiol Biotechnol 23, 242-251.

Christensen, W. B. (1946). Urea decomposition as a means of differentiating Proteus and paracolon cultures from each other and from Salmonella and Shigella types. J Bacteriol 52, 461-466.

Collins, C. H., Lyne, P. M. \& Grange, J. M. (1989). Microbiological Methods, 6th edn. London: Butterworth.

Felsenstein, J. (1993). PHYLIP - phylogeny inference package, version $3.5 \mathrm{c}$. Distributed by the author. Department of Genome Sciences, University of Washington, Seattle, USA.

Fujii, K., Urano, N., Ushio, H., Satomi, M. \& Kimura, S. (2001). Sphingomonas cloacae sp. nov., a nonylphenol-degrading bacterium isolated from wastewater of a sewage-treatment plant in Tokyo. Int J Syst Evol Microbiol 51, 603-610.

Goel, A. K., Rajagopal, L. \& Sonti, R. V. (2001). Pigment and virulence deficiencies associated with mutations in the aroE gene of Xanthomonas oryzae pv. oryzae. Appl Environ Microbiol 67, 245-250.
Gordon, R. E., Barnett, D. A., Handerhan, J. E. \& Pang, C. H.-N. (1974). Nocardia coeliaca, Nocardia autotrophica, and the nocardin strain. Int J Syst Bacteriol 24, 54-63.

Jenkins, C. L., Andrewes, A. G., McQuade, T. J. \& Start, M. P. (1979). The pigment of Pseudomonas paucimobilis is a carotenoid (nostoxanthin), rather than a brominated aryl-polyene (xanthomonadin). Curr Microbiol 3, 1-4.

Jukes, T. \& Cantor, C. R. (1969). Evolution of protein molecules. In Mammalian Protein Metabolism, pp. 21-132. Edited by H. N. Munro. New York: Academic Press.

Kaur, H., Cortes, J., Leadlay, P. \& Lal, R. (2001). Cloning and partial characterization of putative rifamycin biosynthetic gene cluster from actinomycete Amycolatopsis mediterranei DSM 46095. Microbiol Res 165, 239-246.

Kiyohara, H., Nagao, K., Kouno, K. \& Yano, K. (1982). Phenanthrene degrading phenotype of Alcaligenes faecalis AFK2. Appl Environ Microbiol 43, 458-461.

Kuykendall, L. D., Roy, M. A., O’Neill, J. J. \& Devine, T. E. (1988). Fatty acids, antibiotic resistance, and deoxyribonucleic acid homology groups of Bradyrhizobium japonicum. Int J Syst Bacteriol 38, 358-361.

Maruyama, T., Park, H.-D., Ozawa, K., Tanaka, Y., Sumino, T., Hamana, K., Hiraishi, A. \& Kato, K. (2006). Sphingosinicella microcystinivorans gen. nov., sp. nov., a microcystin-degrading bacterium. Int J Syst Evol Microbiol 56, 85-89.

McCarthy, A. J. \& Cross, T. (1984). A taxonomic study of Thermomonospora and other monosporic actinomycetes. J Gen Microbiol 130, 5-25.

Miller, L. T. (1982). A single derivatization method for bacterial fatty acid methyl esters including hydroxyl acids. J Clin Microbiol 16, 584-586.

Pal, R., Bala, S., Dadhwal, M. \& 8 other authors (2005). Hexachlorocyclohexane-degrading bacterial strains Sphingomonas paucimobilis B90A, UT26 and $\mathrm{Sp}+$, having similar lin genes, represent three distinct species, Sphingobium indicum sp. nov., Sphingobium japonicum sp. nov. and Sphingobium francense sp. nov., and reclassification of [Sphingomonas] chungbukensis as Sphingobium chungbukense comb. nov. Int J Syst Evol Microbiol 55, 1965-1972.

Pipe, R. K. \& Moore, M. N. (1986). An ultrastructural study on the effects of phenanthrene on lysosomal membranes and distribution of the lysosomal enzyme $\beta$-glucuronidase in digestive cells of the periwinkle Littorina littorea. Aquat Toxicol 8, 65-76.

Saitou, N. \& Nei, M. (1987). The neighbor-joining method: a new method for reconstructing phylogenetic trees. Mol Biol Evol 4, 406-425.

Samanta, S. K., Chakraborti, A. K. \& Jain, R. K. (1999). Degradation of phenanthrene by different bacteria: evidence for novel transformation sequences involving the formation of 1-naphthol. Appl Microbiol Biotechnol 53, 98-107.

Takeuchi, M., Hamana, K. \& Hiraishi, A. (2001). Proposal of the genus Sphingomonas sensu stricto and three new genera, Sphingobium, Novosphingobium and Sphingopyxis, on the basis of phylogenetic and chemotaxonomic analysis. Int J Syst Evol Microbiol 51, 1405-1417.

Thompson, J. D., Gibson, T. J., Plewniak, F., Jeanmougin, F. \& Higgins, D. G. (1997). The CLUSTAL_X windows interface: flexible strategies for multiple sequence alignment aided by quality analysis tools. Nucleic Acids Res 25, 4876-4882.

Tindall, B. J. (1990a). A comparative study of the lipid composition of Halobacterium saccharovorum from various sources. Syst Appl Microbiol 13, 128-130.

Tindall, B. J. (1990b). Lipid composition of Halobacterium lacusprofundi. FEMS Microbiol Lett 66, 199-202. 
Ushiba, Y., Takahara, Y. \& Ohta, H. (2003). Sphingobium amiense sp. nov., a novel nonylphenol-degrading bacterium isolated from a river sediment. Int J Syst Evol Microbiol 53, 2045-2048.

Wayne, L. G., Brenner, D. J., Colwell, R. R. \& 9 other authors (1987). International Committee on Systematic Bacteriology. Report of the ad hoc committee on reconciliation of approaches to bacterial systematic. Int J Syst Bacteriol 37, 463-464.

Yabuuchi, E., Yano, I., Oyaizu, H., Hashimoto, Y., Ezaki, T. \& Yamamoto, H. (1990). Proposal of Sphingomonas paucimobilis gen. nov. and comb. nov., Sphingomonas parapaucimobilis sp. nov., Sphingomonas yanoikuyae sp. nov., Sphingomonas adhaesiva sp. nov., Sphingomonas capsulate comb. nov. and two genospecies of the genus Sphingomonas. Microbiol Immunol 34, 99-119.

Yabuuchi, E., Kosako, Y., Fujiwara, N., Naka, T., Matsunaga, I., Ogura, H. \& Kabayashi, K. (2002). Emendation of the genus Sphingomonas Yabuuchi et al. 1990 and junior objective synonymy of the species of three genera, Sphingobium, Novosphingobium and Sphingopyxis, in conjunction with Blastomonas ursincola. Int J Syst Evol Microbiol 52, 1485-1496. 